\title{
RANCANG BANGUN SISTEM ALAM PENDETEKSI BANJIR BERBASIS ARDUINO UNO
}

\author{
Suradi $^{1}$, Ahmad Hanafie ${ }^{2}$, Sahir Leko ${ }^{3}$ \\ 1,2 Prodi Studi Teknik Industri, Fakultas Teknik, Universitas Islam Makassar \\ ${ }^{3}$ Program Studi Teknik Informatika, Fakultas Teknik, Universitas Islam Makassar \\ Email:suradi.dpk@uim-makassar.ac.id, ahmadhanafie.dty@uim-makassar.ac.id \\ syahirleko88@gmail.com
}

\begin{abstract}
ABSTRAK
Banjir merupakan bencana alam yang sering terjadi dan menjadi salah satu fokus perhatian pemerintah, karena masih banyak menimbulkan kerugian dan korban jiwa. Banjir dapat terjadi akibat meluapnya air, karena itu diperlukan sebuah sistem untuk mendeteksi sedini mungkin terhadap perubahan level ketinggian air. Penelitian ini bertujuan untuk mambangun suatu sistem dan untuk mengetahui kemungkinan datangnya banjir sebelum banjir terjadi menggunakan peringatan berupa alarm dan pesan teks pendek. Metode penelitian adalah sistem pendeteksi banjir peringatan dini ini dibangun dengan menggunakan Arduino sebagai mikrokontroler yang mengendalikan sensor ultrasonik untuk mendeteksi air, dalam mendeteksi air (kemungkinan banjir) serta ketinggiannya. Pesan pendek akan dikirim oleh sistem dan SMS gateway yang tergantung dari tangkapan sensor ultrasonik. Hasil dari penelitian ini adalah terbangunnya sebuah sistem pendeteksi banjir berbasis Arduino uno ini diharapkan mampu memudahkan pengguna untuk mengetahui keadaan luapan air melalui tiga jenis pesan pendek yaitu status aman dengan ketinggian air $10 \mathrm{~cm}$, status siaga dengan ketinggian air $20 \mathrm{~cm}$, dan status bahaya dengan ketinggian air mencapai $30 \mathrm{~cm}$. Setiap ketinggian air berubah maka sistem merespon dengan mengirim pesan yang sesuai. Kesimpulan penelitian yaitu untuk merancang sebuah alat pendeteksi banjir serta untuk mengetahui proses kerja alat pendeteksi banjir.
\end{abstract}

Kata Kunci : Sensor, HC-SR04, Peringatan dini, Buzzer

\begin{abstract}
Floods are natural disasters that often occur and become one of the focus of government attention, because there are still many losses and casualties. Flooding can occur due to overflow of water, therefore we need a system to detect as early as possible against changes in water level. This study aims to build a system and to determine the possibility of a flood before the flood occurs using warnings in the form of alarms and short text messages. The research method is an early warning flood detection system built using Arduino as a microcontroller that controls ultrasonic sensors to detect water, in detecting water (possible flooding) and its altitude. Short messages will be sent by the system and the SMS gateway which depends on the ultrasonic sensor capture. The results of this study are the establishment of an Arduino uno-based flood detection system that is expected to be able to facilitate users to find out the state of water overflow through three types of short messages namely safe status with water level $10 \mathrm{~cm}$, alert status with water level $20 \mathrm{~cm}$, and hazard status with height the water reaches $30 \mathrm{~cm}$. Every time the water level changes, the system responds by sending the appropriate message. The conclusion of the research is to design a flood detector and to know the work process of a flood detector.
\end{abstract}

Keywords: Sensor, HC-SR04, Early warning, Buzzer

\section{PENDAHULUAN}

Seiring dengan bekembangnya dunia teknologi mengenai pengontrolan otomatis pada zaman sekarang ini, membuat sistem pengontrolan secara otomatis sangat membantu seseorang dalam meringankan pekerjaannsya. Banyak diluar sana yang sudah menggunakan berbagai macam sistem kerja otomatis. Sistem pengontrolan secara otomatis sekarang ini bisa dibuat berbagai macam ragamnya 
seperti pengontrolan sistem pendeteksi banjir secara otomatis untuk memperingati terjadinya banjir (Fahruddin, 2014).

Masalah banjir belum juga terselesaikan khususnya di daerah antang Makassar, Sulawesi selatan contohnya. sering kali mengalami bencana banjir musiman yang terjadi setiap tahunnya yang mengakibatkan kerugian materi yang tidak sedikit. Banjir memang merupakan hal yang harus diantisipasi, apalagi pada daerah rawan banjir, ini merupakan hal serius yang harus diperhatikan oleh pemerintah. Pada beberapa daerah di kota makassar yang sering mengalami bencana banjir ini seperti daerah yang menjadi langganan banjir setiap tahunnya yaitu daerah Kelurahan Antang Makassar, Sulawesi Selatan.

Bencana banjir yang akhir - akhir ini sering terjadi masih menjadi salah satu fokus perhatian pemerintah. pasalnya bencana banjir itu mengakibatkan banyak korban jiwa, serta juga menimbulkan banyak kerugian, baik kerugian materil maupun psikologis. bencana banjir yang sering terjadi nampak tidak ada pencegahan secara efektif untuk meminimalisir korban jiwa, serta juga masih minimnya sistem untuk memberi peringatan sedini mungkin akan datangnya banjir agar kerugian bisa dikurangi. Untuk itu perlu adanya alat pendeteksi banjir jarak jauh, tidak hanya meningkatkan keakuratan pendeteksian pada banjir namun nantinya bisa dipantau secara real time sehingga memberikan kondisi ketinggian air dan siaga banjir disaat yang tepat (Indah Fitri Astuti. 2017).

Penelitian untuk rancang bangun perangkat lunak dan perangkat keras contohnya sudah dilakukan merancang sistem mobile untuk notivikasi kondisi banjir (satria et al, 2017), (anindita et al, 2016) dalam bentuk SMS yang adalah hasil proses sistem mikrokontroler arduino uno atau raspberry Pi dan GSM Modul. Prototipe yang sudah ada tersebut bisa menjadi basis penelitian dan pengembangan untuk penerapan berikutnya.

Berdasarkan barbagai masalah maka peneliti berinisiatif membuat sebuah alat, yang dirancang mampu bekerja untuk mendeteksi banjir secara otomatis dengan sistem kendali yang sesuai dengan flowchart yang dirancang dengan menggunakan sensor ultrasonik dan mikrokontroler arduino uno sebagai kontroler utama.

\section{METODE PENELITIAN}

Alat dan Bahan

Pada penelitian ini metodelogi penelitian yang digunakan adalah SDLC (Software Development Life Cycle) yaitu siklus pengembangan perangkat lunak yang didalamnya terdiri atas siklus dari analisis, desain, implementasi, testing dan pemeliharaan (Dedi Satria 2017).

\section{Metode}

Metode yang digunakan dalam penelitian ini adalah perancangan prototipe sistem peringatan dini banjir berbasis arduino uno dengan tahapan analisis, desain dan implementasi. Perancangan sistem di bangun menggunakan beberapa modul yaitu Arduino Uno, Sensor Ultrasonik, Buzzer, modul SIM 800L dan lampu LED dengan penjelasan modul tersbeut diantaranya:

\section{Perancangan perangkat keras}

Pembuatan sistem peringatan bahaya banjir ini melalui beberapa tahap pembuatan. Langkah pertama adalah mempersiapkan alat dan bahan yang akan digunakan, seperti Arduino uno sensor ultrasonik dan buzzer. Langkah kedua adalah meletakkan komponen-komponen eletronika agar dapat memudahkan dan penyesuaian sistem dalam penggunaannya. Proses berikutnya adalah membuat rangkaian skematik elektronik sistem peringatan dini banjir dimana pada mikrokontroler Arduino uno dihubungkan ke beberapa komponen lainnya seperti Sensor Ultrasonik HC-SR04, Sim8001, buzzer, indicator LED, regulator switching, Baterai, dan beberapa komponen yang lain.

\section{Perancangan LED}

Rancangan LED terdiri dari sebuah LED dan resistor sebesar $100 \mathrm{ohm}$. Kisaran besarnya tahanan yaitu dari $100 \mathrm{ohm}$ hingga $1 \mathrm{k} \mathrm{ohm}$, tergantung dari kebutuhan pemrogram. Semakin besar tahanan maka cahaya yang dihasilkan akan semakin redup (Sofyan 2016).

Lampu LED digunakan sebagai indikator level air dengan output berupa cahaya LED yang menyala apabila level air dalam keadaan bahaya. LED warna merah dihubungkan ke pin A1 arduino uno, warna kuning dihubungkan ke pin A2 arduino uno, sedangkan warna hijau dihubungkan ke pin A3 pada Arduino Uno.

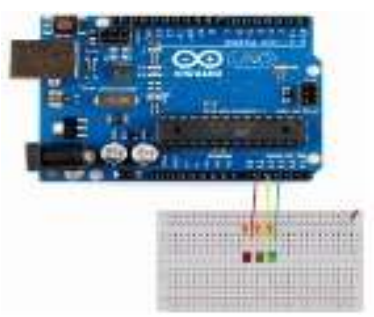

Gambar 1. Perancangan LED

\section{Perancangan Busser}


Buser berfungsi sebagai indikator visual dalam bentuk suara (Adhitya Permana 2015).

Pada perancangan ini buzzer akan aktif ketika titik air melewati batas yang telah di tentukan. Dimana kabel pada buzzer dihubungkan ke pin A0 pada arduno uno

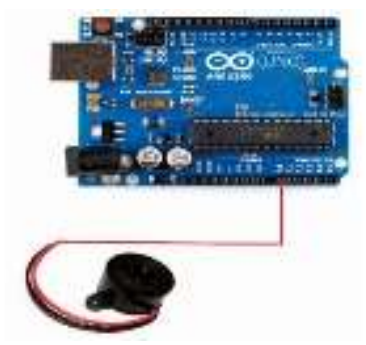

Gambar 2. Perancangan Buzzer

\section{Perancangan Sensor Ultrasonik}

Merupakan sensor jarak yang memanfaatkan gelobang suara ultrasonik didalam proses pengukuran jarak suatu objek (Adhitya Permana 2015).

Pada perancangan ini ensor ultrasonik merupakan rangkaian indikator untuk mendeteksi ketinggian air. Dimana pada rangkaian ini kutub VCC dari sensor dihubungkan ke pin $5 \mathrm{~V}$ pada Arduino, trig ke pin digital 3 arduino, echo dihubungkan pada pin digital 2 arduino dan ground ke ground dari Arduino uno.

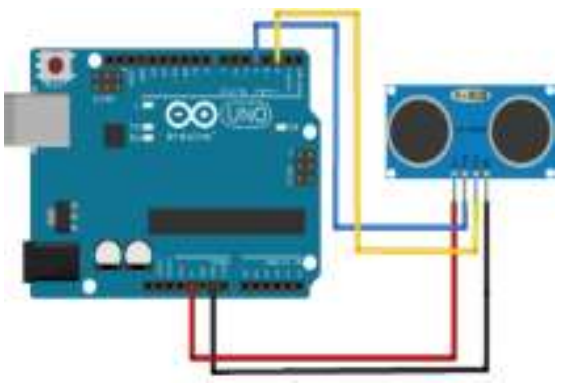

Gambar 3. Perancangan sensor ultrasonik

\section{Perancangan SIM $800 \mathrm{~L}$}

Pada rangkaian ini digunanakan SIM 800L sebagain penanda adanya prubahan ketinggian air melalui Short message service (SMS). Dimana pin TX SIM 800L dihubungkan ke pin digital 7 pada arduino uno dan RX dihubungkan ke pin 8 Arduino uno, sedangkan VCC SIM 800L dihungkan out + pada stop down dan ground SIM 800L dihubungkan ke out mines pada stop down

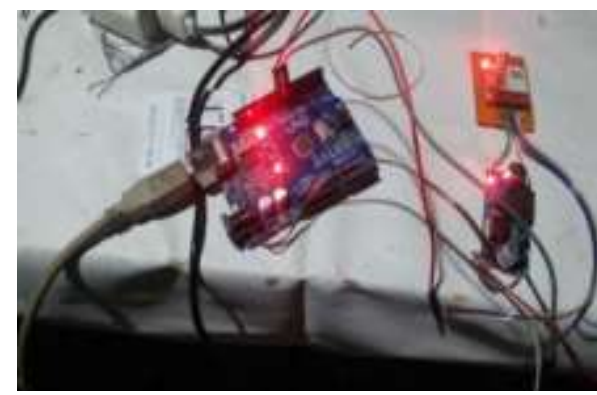

Gambar 4. Perancangan Modul GSM SIM 800L

\section{HASIL DAN PEMBAHASAN}

\section{Pengujian Alat Secara Keseluruhan}

Pengujian ini dilakukan ketika semua komponen telah terpasang pada mikrokontroler arduino uno. Untuk mengetahui kepekaan baca terhadap level air. Hasil uji kemudian di bandingkan dengan lampu led sebagai indicator dan sms sebagai keterangan ketinggian air yang terdapat pada rangkaian. Hasil pengujian ini dapat dilihat pada Tabel 1.

Tabel 1. Hasil pengujian alat secara keseluruhan

\begin{tabular}{|c|c|c|c|}
\hline $\begin{array}{l}\text { Keadisi Leted } \\
\text { Air }\end{array}$ & $\begin{array}{c}\text { Indilikator } \\
\text { (L.ampe Jlengala) }\end{array}$ & $\begin{array}{c}\text { Sess } \\
\text { (Keienasga Kadisi Air) }\end{array}$ & $\begin{array}{c}\text { Bueser } \\
\text { (BuxyiAlene) }\end{array}$ \\
\hline Minimam & 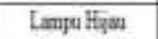 & Amm & Pelin \\
\hline Seding & Lump Kaning & Siags & Selang \\
\hline Maksumam & Lampu Merah & Bahñz & Semahn kera \\
\hline
\end{tabular}

Berdasarkan tabel 1 dapat dijelaskan jika level air air minimum maka lampu hijau akan menyala, buzzer berbunyi secara pelan dan sms akan dikirim ke nomor tujan dengan keterangan status dalam kondisi aman, jika level air sedang makan lampu led kuning akan menyala, buzzer berbunyi dan sms akan di kirim ke nomor tujan dengan keterangan status dalam kondisi siaga, dan jika level air melwati batas maksimum maka lampu merah akan menyala, buzzer berbunyi semakin keras dan sms dikiri dengan keteragan status dalam kondisi bahaya. Hal ini mengindikasikan bahwa alat bekerja dengan baik. Sedangkan menurut Abdul Chobir (2017) bahwa alat yang dihasilkan tidak ditemukan eror dalam pengujian. Dari hasil pengujian yang dilakukan didapat eror pengujian sama dengan nol dengan ketinggian air yang di ukur adalah $30 \mathrm{~cm}, 50$ $\mathrm{cm}, 70 \mathrm{~cm}$

Pengujian pertama dilakukan dengan mengatur ketinggian sensor setinggi $10 \mathrm{~cm}$ di atas permukaan 
air, jika air melewati batas warna hijau yang telah di tentukan maka buzzer akan berbunyi secara pelan seperti gambar dibawah ini.

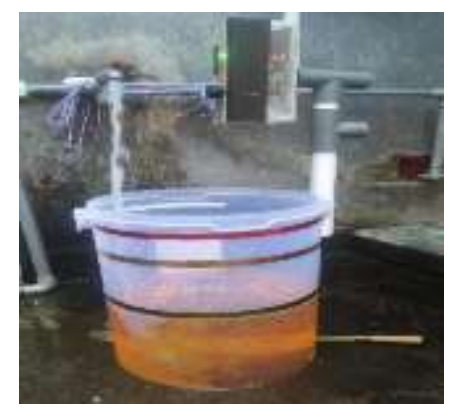

Gambar 5. Hasil pengujian air dalam kondisi aman.

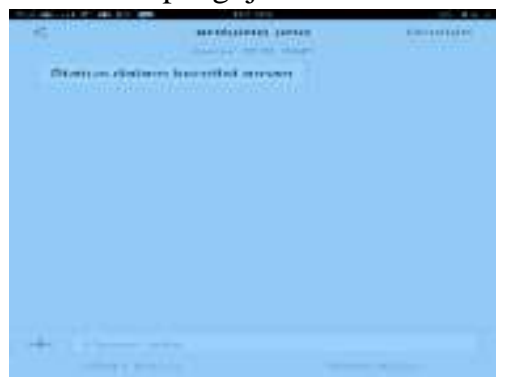

Gambar 6. Hasil pengeriman pesan dari modul GMS, status dalam kondisi aman.

Gambar 6. Dapat dijelaskan bahwa ketika air melewati batas yang telah ditentuka yaitu batas 10 cm maka Modul GSM SIM 800L akan mengirimkan pasan singkat kepada nomoor tujuan dengan keterangan status dalam kondisi aman.

Pengujian kedua dilakukan dengan mengatur ketinggian sensor setinggi $20 \mathrm{~cm}$ di atas permukaan air jika air melewati batas warna kuning maka buzzer akan berbunyi, sepertiyang dilihat pada gambar dibawah ini.

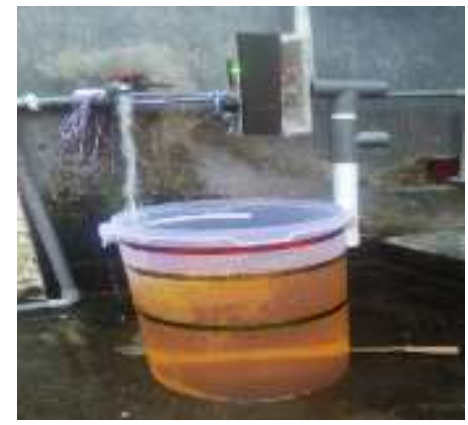

Gambar 7. Hasil pengujian air dalam kondisi siaga
Gambar 8. Hasil pengiriman pesan dari modul GSM, status dalam kondidi siaga

Gambar 8. Dapat dijelaskan bahwa ketika air melewati batas yang telah ditentuka yaitu batas 20 cm maka Modul GSM SIM 800L akan mengirimkan pasan singkat kepada nomor tujuan dengan keterangan status dalam kondisi siaga.

Pengujian ketiga dilakukan dengan mengatur ketinggian sensor setinggi $30 \mathrm{~cm}$ di atas permukaan air jika air melewati batas warna merah maka buzzer akan berbunyi dan pesan akan di kirim ke nomor tujuan. seperti gambar dibawah ini.

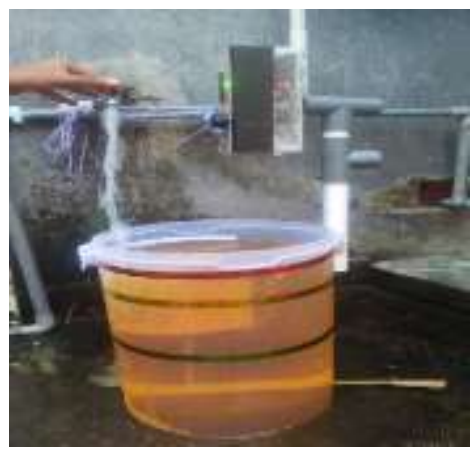

Gambar 9. Hasil pengujian air dalam kondisi bahaya

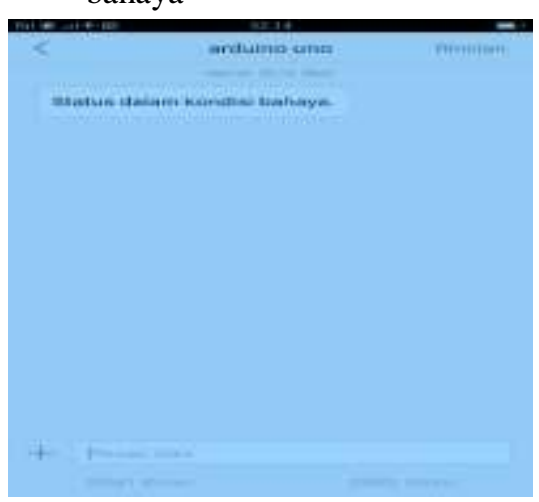

Gambar 10. Hasil pengiriman pesan dari modul GSM, status dalam kondidi siaga

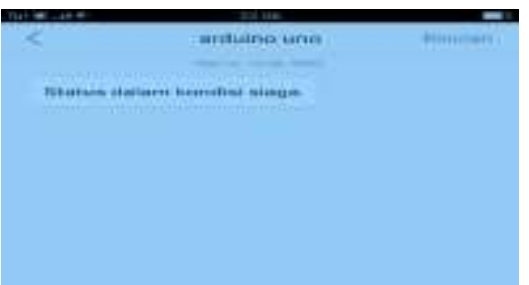


Gambar 10. dapat dijelaskan bahwa ketika air melewati batas yang telah ditentuka yaitu batas 30 cm maka Modul GSM SIM 800L akan mengirimkan pasan singkat kepada nomor tujuan dengan keterangan status dalam kondisi bahaya.

Dari semua kondisi mulai dari kondisi aman. Siaga dan bahaya menurut Indah Fitri Astuti (2017) Pesan sms akan berubah jika sensor ultrsonik mendeteksi ketinggian air berubah dari titik 0 dan terus meningkat hingga di titik $5 \mathrm{~cm}, 10 \mathrm{~cm}, 15 \mathrm{~cm}$.

\section{KESIMPULAN}

Kesimpulan yang di dapat diambil dari penelitian ini yaitu sebagai berikut:

1. Untuk merancang sebuah alat pendeteksi banjir, terdapat beberapa rangkaian yang dibutuhkan yaitu Pertama, regulator switching disini berfungsi untuk menurunkan tegangan listrik yang masuk pada alat. Kedua, sensor ultrasonik yang akan mendeteksi perubahan ketinggian air. Ketiga, Mikrokontoler Arduino Uno berfungsi memproses dan menyimpan data yang dikirm oleh sensor. Keempat, GSM Sim800L jaringan yang digunakan untuk mengirim informasi perubahan ketinggian air berupa Short Message Service kepada nomor hendpone yang telah dimasukkan dalam koding. Kelima, buzzer disini berfungsi untuk mengeluarkan bunyi penanda adanya perubahan ketinggian air. Kelima Rangkaian tersebut harus ada dalam membuat sebuah alat pendeteksi banjir.

2. Proses kerja alat ini dimulai dari sensor ultrasonik yang berfungsi sebagai pendeteksi ketinggian air kemudian dikirim ke mikrikontroler Arduino uno, Arduino uno menyimpan data yang dikirim oleh sensor ultrasonik kemudian diproses setelah itu dikirim ke Handphone secara real time yang nomornya telah ditentukan dalam Coding dengan menggunakan jaringa GSM Sim800L dan bunyi buzzer sebagai penanda adanya perubahan ketinggian air. Pengujian dilakukan dengan cara memasukkan air pada boks yang di isi dengan air dimana pesan akan dikirim ke nomor tujuan dan buzzer akan berbunyi ketika titik air telah melewati batas yang ditentukan yaitu, titik aman $10 \mathrm{~cm}$, titik siaga $20 \mathrm{~cm}$ dan titik bahya banjir $30 \mathrm{~cm}$.

\section{DAFTAR PUSTAKA}

Abdul Chobir1, Asep Andang, Nurul Hiron, 2017, Sistem Deteksi Elevasi Permukaan Air Sungai Dengan Sensor Ultrasonic Berbasis
Arduino, Fakultas Teknik, Universitas Siliwangi Tasikmalaya.

Adhitya permana, dedi Trianto, tedi rismana, 2015, Rancang Bangun Sistem Monitoring Volume Dan Pengisian Air Menggunakan Sensor Ultrasonik Berbasis Mikrokontroler Avr Atmega8.

Alfred Tenggono, Yovan Wijaya, Erick Kusuma, Welly, 2015, Sistem Monitoring Dan Peringatan Ketinggian Air Berbasis Web Dan Sms Gateway, STMIK PalComTech, Palembang.

Dedi Satria, Syaifuddin Yana, Rizal Munadi, Saumi Syahreza.2017, Sistem Peringatan Dini Banjir Secara Real-Time Berbasis Web Menggunakan Arduino Dan Ethernet.

Fahruddin, 2014, Prototype Monitoring Ketinggian Air Pada Waduk Berbasis Mikrokontroler, Jurusan Teknik Informatika Fakultas Sains Dan Teknologi Universitas Islam Negeri Alauddin Makassar

Indah Fitri Astuti, Arton Nuary Manoppo, Zainal Arifin, 2017, Sistem Peringatan Dini Bahaya Banjir Kota Samarinda Mengunakan Sensor Ultrasonic Berbasis Mikrokontroler Dengan Buzzer Dan Sms, Fakultas Ilmu Komputer Dan Teknologi Informasi, Universitas Mulawarman Samarinda

Sofyan, Catur Budi Affianto, Sur Liyan, 2016, Pembuatan Prototipe Alat Pendeteksi Level Air Menggunakan Arduino Uno R3, Program Studi Teknik Informatika, Fakultas Teknik, Universitas Janabadra, Matar 
